\title{
La Filosofía del Cuidado de la Tierra como Ecosofía
}

\author{
The Philosophy of Caring for Earth as Ecosophy
}

IRENE COMINS MINGOL*

\begin{abstract}
Resumen: La historia del pensamiento occidental se ha caracterizado por erigir ciertos centrismos excluyentes y reduccionistas de la realidad. Algunos de esos centrismos son el androcentrismo, el etnocentrismo o el antropocentrismo, respectivamente excluyentes de las mujeres, las culturas no occidentales y la naturaleza. La búsqueda de un pensamiento inclusivo, no reduccionista, ha caracterizado el pensamiento alternativo que se ha ido gestando en las últimas décadas. En este artículo se abordará una de las líneas de trabajo al respecto, la filosofía ecológica, y en concreto el potencial de la filosofía del cuidar como ecosofía. Palabras clave: Ecosofía, reduccionismo, ética del cuidar, ciudadanía ecológica, género
\end{abstract}

\begin{abstract}
The history of Western thought has been characterized by the construction of certain "centrisms" which exclude and reduce our perception of reality. Some of these are androcentrism, ethnocentrism and anthropocentrism, respectively exclusive of women, non-Western cultures and nature. A main objective of the alternative thinking during last decades han been to create a non-reductionist, inclusive thinking. This article will address one of the lines of work in this regard, ecological philosophy, and in particular the potential of the philosophy of care as ecosophy.
\end{abstract}

Keywords: Ecosophy, reductionism, ethics of care, ecological citizenship, gender

Una línea de trabajo fundamental en la actualidad es la de construir una ecosofía, una filosofía ecológica, capaz de tematizar y orientar el gran cambio de ideas que ha tenido lugar en el último medio siglo en relación a la problemática medioambiental. En este artículo se abordará el potencial de la filosofía del cuidar como ecosofía, señalando algunas de las contribuciones de la filosofía del cuidar al pensamiento ecológico. Para ello se ha organizado el texto en tres partes. En la primera se describen brevemente algunos rasgos

Fecha de recepción: 26/06/2014. Fecha de aceptación: 21/12/2014.

* Profesora del Departamento de Filosofía y Sociología de la Universitat Jaume I de Castellón. E-mail: cominsi@ uji.es. Sus líneas de investigación son Filosofía y Epistemología para la Paz, Antropología Filosófica y Filosofía del Género. Algunos de sus artículos más recientes son: (2013): «Philosophical Perspectives on Caring Citizenship», en Peace Review: A Journal of Social Justice, 25(3), 406-413 y (2014): «Rethinking Politics and Conflict Transformation from a Gender Perspective» en Philosophy. Bulgarian Journal of Philosophical Education, volume 23, number 3, 324-336. 
del pensamiento hegemónico occidental y el modo en que han podido ejercer de contexto a la agresión medioambiental. En segundo lugar se presentan las características principales de la filosofía del cuidar, y sus aportaciones como ecosofía, tanto desde un punto de vista teórico-conceptual como práctico. Finalmente se aborda la Carta de la Tierra como ejemplo de Declaración Internacional que asume la filosofía del cuidar como marco de sentido para una nueva conciencia ecológica.

\section{El antropocentrismo en el pensamiento occidental}

La historia del pensamiento occidental se ha caracterizado por ser una historia de encumbramiento del antropocentrismo. ${ }^{1}$ Varios momentos históricos contribuyeron significativamente a ello. Así, por ejemplo, desde finales del siglo III, con la consolidación del cristianismo y el inicio de la filosofía medieval, se empezó a extender la creencia de que los seres humanos estamos hechos a imagen y semejanza de Dios, por tanto en un plano jerárquico superior al resto de seres — animados e inanimados - fruto de la creación divina. Posteriormente con el Renacimiento y el surgimiento de la filosofía moderna, se continuarían ensalzando, ya no desde la fe sino desde el triunfo de la razón sobre ésta, las peculiares capacidades cognoscitivas y normativas del ser humano, un ser humano solipsista, capaz de definirse y ser definido sólo en referencia a sí mismo - sin tener en cuenta a los otros y otras ni al medio ambiente-. Si bien la filosofía contemporánea ha supuesto la apertura a un sujeto relacional y dialógico, el pensamiento occidental hegemónico sigue siendo esencialmente antropocéntrico - tiene en cuenta a los otros y otras pero no al medio ambiente - - Sólo muy recientemente ha aparecido un pensamiento ecológico o ecosofía que «surge como tal durante la primera mitad de los 70, prácticamente al mismo tiempo que el ecologismo como movimiento social; al cual acompaña, tratando de ofrecer una visión de calado sobre la problemática medioambiental» (Arnáiz Ferrer, 2011, 34-35).

\subsection{Sobre la naturaleza: de una visión organicista a otra mecanicista}

El antropocentrismo se ha hecho patente además en el modo que ha evolucionado nuestra visión sobre la naturaleza de manos del pensamiento científico. Existen dos tradiciones importantes en la filosofía del método científico en la historia occidental: la aristotélica y la galileana, que cabe reseñar aquí por su diferente percepción de la naturaleza (Mardones, 1991). La tradición galileana, que se desarrolló desde los siglos XV y XVI, y continúa en la actualidad, sustituyó una visión de la naturaleza organicista y holística - propia de la tradición aristotélica-, por otra mecanicista y reduccionista. En el siglo XIX el positivismo se encargó de llevar hasta sus últimas consecuencias esta visión, y consolidarla como la única cosmovisión posible, que ha acompañado no sólo la revolución industrial, sino también el desarrollo del capitalismo y la globalización.

1 Es importante reconocer que a lo largo de la historia del pensamiento occidental podemos rastrear contribuciones relevantes a la construcción de un pensamiento medioambiental no antropocéntrico. Sin embargo, no es menos cierto que esas corrientes no consiguieron afectar significativamente el modo hegemónico de ver en Occidente la naturaleza y el lugar que los seres humanos ocupamos en ella. 
Una de las principales diferencias entre la tradición aristotélica y la tradición galileana de ciencia radica, pues, en la diferente concepción que albergan sobre la naturaleza.

La tradición aristotélica concebía la naturaleza como un organismo vivo. Una concepción del mundo cercana a la hipótesis Gaia que desarrolló, en 1969, el científico James Lovelock, y según la cual la Tierra tiene reacciones y formas de equilibrio propias de los seres vivos. De tal forma que, según la hipótesis Gaia, la Tierra podría considerarse un superorganismo vivo. Esa era la concepción de la naturaleza en la tradición aristotélica, la de un organismo vivo, no sólo como hipótesis puntual sino como cosmovisión hegemónica. La ciencia aristotélica se basaba en la observación como método y su objetivo era comprender el telos, la finalidad con la que ocurrían los fenómenos.

La tradición galileana de ciencia rompería esa visión organicista para imponer otra mecanicista, lo que contribuiría a afianzar la visión del ser humano ocupando un lugar jerárquicamente superior en la naturaleza, que es objetivada y, que como tal, puede ser sujeta a relaciones instrumentalizadas al beneficio del crecimiento económico e industrial. Según Bacon, padre de la ciencia moderna, el conocimiento científico y la invenciones a las que conduce, no «ejercen solamente una ligera guía sobre el curso de la naturaleza; tiene el poder de conquistarla y subyugarla, de sacudirla en sus cimientos» (Shiva, 1991, 39). Así pues, no se trata de una mera concepción de la naturaleza sin consecuencias, sino que describe sin tapujos el espíritu motriz de este modelo de ciencia: la búsqueda del dominio y el control de la naturaleza. El objetivo no es comprender la finalidad de los fenómenos de la naturaleza, sino explicar cómo funcionan determinados aspectos del mundo, atendiendo a una lógica claramente antropocéntrica. Esta transformación de la naturaleza de una madre viva y nutricia en una materia inerte y manipulable se adaptaba perfectamente a la exigencia de explotación del capitalismo naciente, tal y como han denunciado agudamente autoras como Carolyn Merchant $(1980,182)$ o Vandana Shiva $(1991,45)$.

Mientras que las metáforas organicistas de la naturaleza se basan en los conceptos de interconexión y reciprocidad, la metáfora de la naturaleza como una máquina se basa en el postulado de la separabilidad y manipulabilidad (Shiva, 1991, 45). Vandana Shiva lo ilustra perfectamente cuando señala que en el paradigma reduccionista de la tradición galileana «un bosque se reduce a madera comercial y la madera se reduce a celulosa para las industrias que fabrican pulpa de madera y papel» $(1991,47)$. El reduccionismo último consiste en vincular la naturaleza con una visión de la actividad económica en la cual el dinero es el único patrón de valor y riqueza $(1991,48)$.

En defensa de la ciencia moderna se arguye que no es la ciencia en sí sino el mal uso político y la aplicación tecnológica carente de ética lo que conduce a la violencia. Siempre resultó claro que este argumento era engañoso, pero hoy es totalmente insostenible ya que la ciencia y la tecnología se han vuelto inseparables desde el punto de vista cognoscitivo, y la amalgama ha sido incorporada al complejo científico, militar e industrial del patriarcado capitalista (Shiva, 1991, 54).

Obviamente, el problema no consiste sólo en si se usa bien o mal la tecnología sino que radica en la cosmovisión de partida y en el proceso mismo de conocimiento-creación en la ciencia moderna $(1991,58)$. 


\subsection{El ser humano en el cosmos: necesidad de una nueva autoconciencia}

La relación del ser humano con la Tierra está necesitada de refundación. Como hemos visto, la historia del pensamiento y de la ciencia occidental ha situado a la Tierra en un plano diferente e inferior al del ser humano. Sin embargo, no debemos olvidar, que «tenemos Tierra en nuestros adentros» (Boff, 2002, 58). La etimología de la palabra humano bien nos lo ilustra, su raíz humus significa tierra. Por ello, ser conscientes de nuestra terrenalidad es el primer paso para la construcción de una nueva concepción del ser humano, abierta a la dimensión ecológica. Además, esta toma de conciencia de nuestra terrenalidad nos hace humildes. La palabra humildad, humilis, se encuentra etimológicamente emparentada con humus, y significa de poca altura, cercano a la tierra. La humildad nos permite despegarnos de la arrogancia de creernos como Dioses (Martínez Guzmán, 2005, 80-81). Descubrir que no existe distancia entre nosotros y la Tierra, que estamos formados por las mismas energías, por los mismos elementos físico-químicos, es el primer paso en esa nueva autoconciencia.

La filosofía debería orientarnos y ayudarnos a tomar conciencia de esa profunda unidad. Lamentablemente esa es una de las deficiencias de la filosofía occidental de todos los tiempos. Según Jesús Mosterín la filosofía, y en general toda reflexión crítica actual, adolece de tres insuficiencias. «Una filosofía satisfactoria nos proporcionaría una cosmovisión global científicamente aceptable, nos señalaría el camino de la buena vida posible y nos ayudaría a sintonizar con la realidad última del universo» (Mosterín, 1994, 27). Estas insuficiencias corresponden respectivamente al ámbito teórico, práctico y espiritual. Nos interesa destacar aquí el último punto, la necesidad de desarrollar en el ser humano una conciencia cósmica de comunión con el universo. Jesús Mosterín califica la historia del pensamiento occidental de tremendamente antropocéntrica, resultado de los delirios de una autoconciencia aislada $(2003,211)$. Una nueva conciencia ecológica necesita partir del anclaje de la autoconciencia en la conciencia cósmica. «La solución de los problemas ecológicos actuales (de la que depende el destino de la vida y de la humanidad sobre la Tierra) pasa por una nueva religiosidad, no dogmática e irracional, sino racional y filosófica, que combine la comprensión científica con la reverencia emocional y la comunión mística» (Mosterín, 1994, 27).

Este tema tiene un cariz espiritual que le ha mantenido alejado del discurso académico al uso, por haberse considerado subjetivo y acientífico. Tan sólo el discurso religioso, y alguna parte del literario, lo han abordado con cierto éxito hasta ahora. Pero en los últimos años, y desde diferentes ámbitos, surgen autores que introducen esta reflexión en el discurso académico. Haber olvidado nuestra unión con la Tierra dio origen al antropocentrismo. Sin embargo, el hecho de que podamos pensar la Tierra, alejarnos de ella para verla mejor, no debe romper el cordón umbilical que nos une a ella (Boff, 2002, 62). Además esta conciencia cósmica puede ser considerada claramente un valor moral, por las implicaciones que deriva en la conducta de los individuos no sólo para el medio ambiente sino también para la paz.

Según Leonardo Boff hay razones para la esperanza, que nos permiten vislumbrar en el horizonte la transición hacia esa nueva autoconciencia ecológica. Boff resume en cinco los grandes momentos de la historia universal y humana (2002, 59-60): Cósmico: el universo en proceso de expansión irrumpe en el escenario, nosotros estábamos ahí, en las posibilidades contenidas en ese proceso. Químico: a medida que se fueron densificando los diferentes cuerpos celestes se formaron los elementos que constituyen cada uno de los seres, el oxígeno, 
el carbono, el nitrógeno y otros; los mismos elementos químicos que circulan por nuestro cuerpo. Biológico: hace aproximadamente unos 3.800 millones de años surgió la vida en la Tierra. Humano: hace 10 millones de años aparece el ser humano, que ha sometido a todas las demás especies, - a excepción de la mayoría de los virus y de las bacterias - ; se trata del peligroso triunfo de la especie homo sapiens y demens. Planetario: la humanidad se descubre a sí misma con el mismo origen y el mismo destino que todos los demás seres y que la Tierra, aparece una nueva autoconciencia.

\section{La filosofía del cuidar como ecosofía}

El pensamiento antropocéntrico occidental está siendo señalado, en los últimos años, como fuente de legitimación de la relación de desigualdad del ser humano sobre la naturaleza y, por tanto, como una de las causas de los problemas medioambientales. Por ello, el pensamiento ecologista alternativo considera importante empezar por dirigir la mirada a las voces excluidas, silenciadas, por el pensamiento antropocéntrico hegemónico: la de las mujeres y la de los pueblos occidentales (Comins Mingol y París Albert, 2012). Las principales aportaciones ecologistas provenientes de estas dos voces comparten algunos puntos en común: una visión que concibe a la vida como sagrada, a la tierra como madre y a sus seres como profundamente interconectados. Un excelente ejemplo de esa cosmovisión biocéntrica alternativa a la visión antropocéntrica lo encontramos en las palabras del gran jefe Seattle en su carta a Franklin Pierce, decimocuarto presidente de los Estados Unidos en 1854 «¿Cómo se puede comprar o vender el cielo o el calor de la tierra? Esa es para nosotros una idea extraña. Cada parte de esta tierra es sagrada para mi gente»².

En este artículo nos vamos a centrar en las aportaciones del legado de las mujeres a la construcción de ese nuevo ethos ecológico. Y lo haremos empezando, como no podría ser de otro modo, por el ecofeminismo, una de las primeras corrientes en denunciar el sesgo antropocéntrico del modelo moderno de desarrollo y de ciencia y de señalarlo como fundamento de la crisis ecológica.

Es interesante señalar, antes de continuar, el lugar en el que se sitúa el ecofeminismo y nuestra propuesta del cuidado como ecosofía, en el marco de las diferentes éticas medioambientales. Podríamos a grosso modo esquematizar las diferentes éticas ecológicas en tres grandes ámbitos o corrientes (Ferrete Sarriá, 2009). Una primera corriente que podemos calificar de antropocéntrica-ortodoxa, que considera que no es necesario crear una nueva ética, una ética ad hoc para abordar la problemática medioambiental a la que asiste la humanidad, sino que los valores tradicionales de la ética, como podría ser el de la austeridad, son los mismos que necesitamos en este nuevo desafío. Ahora bien, se reconoce desde esta corriente la importancia de reforzar y ampliar nuestro sentido de responsabilidad, por ejemplo a lo no intencionado. Existe una segunda corriente que podríamos denominar liberacionista o de derechos de los animales, que reivindica ampliar la comunidad moral a los animales no humanos. Esta corriente ha sido objeto de diferentes polémicas sobre todo en

2 Las palabras del jefe indio Seattle han sido objeto de diferentes versiones, y aunque no se pone en duda la existencia histórica del discurso de 1854, no hay acuerdo sobre la exactitud de las palabras en los relatos del mismo. Puede consultarse una versión de la carta en la página web: http://es.wikisource.org/wiki/Mensaje_del_ Gran_Jefe_Seattle,_de_la_tribu_Dewamish,_al_Presidente_de_los_Estados_Unidos_Franklin_Pierce. 
lo concerniente a discernir qué tipo de animales son entidades morales, y el modo en que de nuevo el antropocentrismo - el nivel de semejanza al ser humano- parece determinar esa jerarquización. Una tercera corriente de ethos ecológico podemos calificarla de biocéntrica y en ella participan diferentes propuestas entre las que se encuentra el ecofeminismo y el pensamiento ecocéntrico proveniente de otras culturas no occidentales. La propuesta de la filosofía del cuidado como ecosofía, que proponemos en este artículo, se situaría en esta tercera propuesta, que reivindica la necesidad de un nuevo ethos no antropocéntrico, basado en el reconocimiento de la íntima interconexión del ser humano con la naturaleza.

Surgido en la década de los 70 del siglo XX, el ecofeminismo es un movimiento que aúna ecología, pacifismo y feminismo, radicando su potencial epistemológico justamente en su capacidad por visibilizar las conexiones existentes entre ellos ${ }^{3}$. Además,

en tanto comprensión filosófica del mundo y praxis emancipatoria, el ecofeminismo es una forma del feminismo que asume específicamente el análisis de los componentes patriarcales de la crisis ecológica y se esfuerza en encontrar soluciones civilizatorias alternativas, incluyendo la revisión y corrección de los discursos, prácticas y formas de organización ecologistas que conserven sesgos patriarcales (Puleo, 2011b, 185).

Vandana Shiva, una de las más reconocidas representantes del ecofeminismo, denuncia el modo en que el concepto moderno de ciencia ha venido acompañado de una concepción del mundo «muerto, infrahumano y artificial» (Ubric Rabaneda, 2011, 342). Según Shiva la ciencia moderna occidental y el desarrollo, son proyectos patriarcales que sirven para dominar, destruir, y subyugar tanto a la mujer, como a la naturaleza y las culturas no occidentales (Shiva, 1991, 37). Por ello en lugar de hablar de desarrollo Vandana Shiva prefiere denominarlo maldesarrollo. Para Shiva el conocimiento científico, de tradición galileana, que sirve de basamento al así denominado desarrollo es en sí una fuente de violencia. «El maldesarrollo encuentra basamento y justificación intelectual en las categorías reduccionistas del pensamiento y la acción científicos» (Shiva, 1991, 37). El modelo de ciencia occidental positivista, se construye sobre tres pilares: uniformidad, centralización y dominación. «Las tendencias reduccionistas y universalizadoras de semejante 'ciencia' se volvieron inherentemente violentas y destructivas en un mundo que es inherentemente interrelacionado y diverso» (Shiva, 1991, 37). La ciencia moderna occidental se ha impuesto sobre todos los demás sistemas de creencias y conocimientos, justificándose bajo una supuesta universalidad y neutralidad. Sin embargo, sus orígenes son concretos y específicos, un proyecto del hombre europeo de los siglos XV al XVII. Gracias al éxito de la ciencia moderna como proyecto masculino pudieron calmarse los temores respecto a la naturaleza y la mujer, con la naturaleza reducida a su substrato mecánico y la mujer a su virtud sexual, la esencia de la Mater podía ser domesticada y conquistada a la vez (Keller, 1985, 60).

Según la filósofa estadounidense Karen Warren (1987) existe una misma lógica de la dominación funcionando en los marcos conceptuales opresivos del sexismo y del naturismo. La opresión de la mujer y de la naturaleza estarían conectadas por un marco conceptual

3 Puede consultarse un estudio sobre los diferentes tipos de ecofeminismos - esencialistas, constructivistas, clásico, postcolonial, etc. - en Alicia Puleo (2013: 25-41). 
caracterizado por tres componentes: 1 . Un pensamiento vertical jerarquizado, en el que se diferencia lo que está arriba de lo que está abajo. 2. Un pensamiento generador de dualismos, en el que las identidades son opuestas y mutuamente excluyentes, y en el que se atribuye un mayor valor a uno de los polos en la dicotomía. 3. Una lógica de la dominación según la cual la parte más valiosa o superior está legitimada para subordinar a la inferior.

Frente a la lógica excluyente de la dominación y de la acumulación económica, cabe promover la lógica alternativa de la sostenibilidad de la vida, una lógica que está construida sobre el eje relacional del cuidado. El sentido de interdependencia y de interrelación dentro de la comunidad de la vida forma parte fundamental de la ética del cuidado, y puede contribuir significativamente a la construcción de una conciencia holística biocéntrica. Cabe decir que esta reivindicación del cuidado la hacemos, como otras autoras (Puleo, 2011a; Magallón, 2006), desde una visión constructivista y no esencialista, en la que se busca una desgenerización y universalización de los valores de la ética del cuidado. La atribución histórica del cuidado a las mujeres ha desarrollado en ellas unas determinadas habilidades morales de priorización del mantenimiento de las conexiones, de sostenibilidad y cuidado de la vida, que son extrapolables al ámbito público y ecológico. Y es que el cuidado tiene tres dimensiones inseparables (Fernández Herrería y López López, 2010: 14-15): una dimensión interna —de relación de cuidado con mi vida - , una dimensión social — cuidando la vida de los demás - , y una dimensión ecológica - el cuidado de la vida natural - . El hecho de que a las mujeres se les haya asignado como parte de su rol de género el cuidado, ha favorecido el desarrollo de una cosmovisión biocéntrica. Son diferentes las investigadoras que han reivindicado la filosofía del cuidar como marco para un nuevo ecologismo, no patriarcal, no reduccionista. Así, por ejemplo la filósofa australiana Val Plumwood reprocha el sesgo androcéntrico de la solución del yo expandido de la Ecología Profunda propuesta por Arne Naess. En contraste aboga por una aproximación ecológica que integre los valores del cuidado, menospreciados por la cultura patriarcal (Plumwood, 1993). Otras autoras, como la economista Mary Mellor, llaman la atención sobre el contraste entre una economía capitalista depredadora y otra doméstica de las mujeres y de los pueblos no integrados en el mercado (Mellor, 1997).

Lamentablemente el cuidado, como valor y como práctica, ha sido minusvalorado a lo largo de la historia del pensamiento occidental, del mismo modo que, de forma paralela, se excluían a los sujetos a los que se atribuían estas tareas: mayoritariamente las mujeres de todas las culturas, pero también hombres de otros pueblos no occidentales. Como señala Claudia Card (1995), la desigual atribución de las tareas del cuidar no responde exclusivamente a una problemática de género sino de opresión social más general. Ese ostracismo sociológico y epistemológico al que se ha visto sometido el cuidar en la cultura occidental, se ha visto reforzado desde inicios del siglo XX a través del poder de la ciencia y la técnica, y el desarrollo de la globalización económica o globalismo. De ahí la necesidad de recuperar el cuidado como ethos fundamental de lo humano, el cuidado como modo-de-ser esencial (Boff, 2002).

La historia del pensamiento occidental podría describirse como una historia paulatina, pero perseverante, de construcción de una racionalidad que atenta contra la sostenibilidad de la vida en favor de la acumulación económica (Magallón, 2006, 270). Frente a esa lógica de la acumulación económica, la lógica de la sostenibilidad de la vida concede un lugar prioritario a la supervivencia, al mantenimiento de la salud, a las tareas de la repro- 
ducción y el cuidado de la especie, tareas que además de mantener la vida proporcionan una comprensión práctica de que la naturaleza ha de preservarse si queremos sobrevivir. Esa lógica de la sostenibilidad de la vida es una lógica desarrollada por las mujeres en el seno de su histórica atribución y socialización en las actividades del cuidar. Y es que «las protagonistas de la supervivencia en la mayor parte del planeta son mujeres» (Magallón, 2006, 271). «Las mujeres producen, reproducen, consumen y conservan la biodiversidad, son las guardianas de las semillas desde tiempos inmemoriales, saben conservar el equilibrio y la armonía» (Ubric Rabaneda, 2011, 345). Esa sabiduría desarrollada por las mujeres para la supervivencia es un legado que viene de lejos, transmitido de unas generaciones a otras, pero todavía no universalizado; es un legado que puede y debe desgenerizarse. La defensa de las subculturas femeninas como fuente de aprendizaje de esa lógica de la sostenibilidad de la vida, no va encaminada a rescatar una esencia eterna de mujer sino «a rescatar y universalizar su experiencia civilizatoria, proponiéndola como modelo para hombres y mujeres» (Magallón, 2006, 276). No podemos permitirnos ningunear la relevancia de los saberes del cuidar como fuente de aprendizaje de competencias de sostenibilidad de la vida. Teniendo especialmente en cuenta, además, cómo a través de las tareas de atención y cuidado se maximizan la utilidad de los recursos disponibles para la satisfacción de las necesidades básicas (PNUD, 1999).

El cuidado es más que un acto individual o que una virtud al lado de otras, es un modode-ser. Como señala Leonardo Boff hay dos maneras básicas de ser-en-el-mundo: el trabajo y el cuidado. De estas dos, el modo-de-ser-en-el-mundo exclusivamente como trabajo puede destruir el planeta $(2002,80)$. De ahí la urgencia de rescatar el modo-de-ser-cuidado. Esa recuperación del cuidado, no tiene lugar a costa del trabajo, sino mediante una forma diferente de entender y de realizar el trabajo. Para ello, el ser humano necesita volver sobre sí mismo y descubrir su modo-de-ser-cuidado $(2002,81)$. Muchas veces hemos olvidado que somos cuidado, como nos recuerda la fábula-mito del cuidado, de Higino, el cuidado es anterior al espíritu (Júpiter) y al cuerpo (Tierra), pues fue Cuidado quien primero modeló al ser humano. El cuidado es además el eje vertebral y definitorio de la intersubjetividad humana. El cuidado como factum originario, da respuesta a la inherente fragilidad y vulnerabilidad del ser humano, constituyéndose en elemento vertebrador de su mundo de la vida. Pero el cuidado es además un telos, un camino a seguir, apuntando a las diferentes formas en que la socialización en el valor del cuidado y la práctica del cuidado contribuye a la paz (Comins Mingol, 2010, 75).

Como señala María Novo, necesitamos un cambio de paradigma, un cambio de mirada, que posibilite un desarrollo humano sostenible (2006). A la construcción de ese nuevo paradigma puede contribuir significativamente una ética del cuidado. Ese paradigma incluiría un mosaico de valores y habilidades morales: la mirada atenta, la calma, la perseverancia, la paciencia, la responsabilidad, el compromiso, el acompañamiento o la empatía son algunos de los componentes que integran ese modo-de-ser-en-el-mundo que es el modo-de-sercuidado. Muchos de los valores de ese mosaico del cuidar comparten una determinada concepción del tiempo, pausada, distendida, porque el cuidado de la vida precisa de atención y paciencia, y no es amigo de la velocidad ni de la prisa. María Novo ha señalado en diferentes textos la interesante relación entre lentitud y sostenibilidad $(2010,47)$ y es que la huella ecológica, puesta tan de moda en los últimos años no es más que un criterio de medida de 
tiempo, del tiempo de desfase entre nuestros ritmos de consumo, y depredación del planeta, con los ritmos de regeneración de la naturaleza. Lograr conciliar nuestros ritmos con los de la biosfera y evitar, haciendo alusión al famoso libro de Jared Diamond (2006), el colapso, es uno de los grandes retos que la humanidad tiene pendientes. Desperdiciar la aportación de una filosofía del cuidar en ese propósito es un lujo que no deberíamos permitirnos.

Según Deane Curtin (1996) el ecofeminismo implica un cambio de una concepción de la ética como cosa de leyes y derechos a una ética que sitúa en el centro los valores del cuidado, el amor y las relaciones de reciprocidad. La práctica ecológica no debería basarse sólo en la referencia filosófica a la tradición de derechos y obligaciones, ya que esa tradición es insuficiente como motor para adoptar una actitud ecológica, profunda y como estilo de vida. La filosofía del cuidar como epistemología inclusiva y no reduccionista supera la dicotomía entre ética de la justicia y ética del cuidado, para buscar una justicia cuidadosa y un cuidado con criterios de justicia. La perspectiva de la ética de la justicia, por sí sola, no tiene en cuenta la interconexión del ser humano con el conjunto de seres. Frente a ella, la perspectiva de la ética del cuidado tiende a ver al ser humano como un sujeto relacional más que autónomo y es consciente de las múltiples posibilidades de acción y práctica ecológica. Desde la ética del cuidado lo prioritario en la moral es el mantenimiento de las relaciones, de la interconexión, no sólo a nivel interpersonal, como ya señaló Carol Gilligan, sino que esa interconexión se amplía al ámbito natural, a la interconexión con la naturaleza.

Esa relación con la naturaleza espiritual y no meramente instrumental incorpora una virtud muy especial: la gratitud (Bardsley, 2013). La gratitud nos habla del reconocimiento de una mayor interconexión, superior a la que se da en una relación por deber. Proteger al medio natural como un deber, supone además una visión antropocéntrica ya que formaría parte de un deber más general, el de proteger los intereses humanos.

La ética del cuidado pone como centro de la moralidad la vida, mientras que la ética de la justicia pone en el centro de la moralidad las normas universales abstractas. Poner en el centro el bienestar de la vida es la llave hacia un cuidado amoroso de la tierra y de la propia humanidad.

Habíamos señalado anteriormente la importancia de reconstruir un nueva autoconciencia en la que el ser humano reconozca su terrenalidad, y también con ello realice un ejercicio de humildad. Y es que la actitud cuidadora es opuesta a la feria de las vanidades, depredadora de la naturaleza y de nosotros mismos, que ha caracterizado el pensamiento hegemónico en las últimas décadas. Frente a la feria de las vanidades como descripción de la vida humana, el cuidado como descripción de la vida humana. «El cuidado es la fuerza principal que se opone a la ley de la entropía, el desgaste natural de todas las cosas, pues todo lo que cuidamos dura mucho más» (Boff, 2004, 22).

\section{Dimensiones prácticas de la filosofía del cuidar}

\subsection{Mujeres y Movimientos Ecologistas}

Las aportaciones de la filosofía del cuidar como ecosofía no se reducen al nivel teóricoconceptual sino también al práctico. Ejemplo de ello es la activa participación de las mujeres 
en movimientos ecologistas a lo largo del mundo. Señalamos, a modo de ejemplo, algunos de estos movimientos en este apartado, con el propósito de mostrar el modo en que la socialización en los valores del cuidar ha contribuido a la construcción de un ethos ecológico en muchas mujeres en todo el mundo.

Los programas que desarrolla Vandana Shiva en el marco de la organización Navdanya, son un buen lugar para iniciar lo que sólo puede ser, debido a cuestiones de espacio, una selección parcial de los movimientos ecologistas liderados por mujeres que existen en el mundo. Navdanya es una red de conservación de semillas y productos ecológicos fundada por Vandana Shiva, en el marco de la cual se llevan a cabo diferentes actividades y programas (Ubric Rabaneda, 2011, 348-350).

Otro de los movimientos ecologistas más conocidos, es el movimiento Chipko, liderado por mujeres campesinas de la India con el objetivo de proteger los bosques, ríos y tierras de las acciones nefastas de la revolución verde y del capitalismo. Su éxito reside en la filosofía gandhiana que lo orienta y los métodos de resistencia noviolenta que utiliza, como el de abrazar los árboles o boicotear las subastas madereras.

Otro movimiento ecologista liderado por mujeres, es el de Las Trece Abuelas Indígenas, ancianas procedentes de diferentes grupos indígenas del Planeta (Círculo Polar Ártico, América del Note, del Sur y Central, África, Tíbet y Nepal) que trabajan unidas para transmitir su sabiduría y sus conocimientos ancestrales, preservándolos para las generaciones futuras.

Muy relevante ha sido el Movimiento Cinturón Verde en Kenia, promovido por la premio Nobel de la Paz Wangari Mathai, y que logró llenar de vegetación una tierra inhóspita, que apenas ofrecía recursos para sus habitantes. Las mujeres involucradas en este movimiento han plantado en Kenia más de 30 millones de árboles (Rivas, 2009, 250).

Estos son algunos ejemplos de cómo la histórica atribución del cuidar a las mujeres ha desarrollado en ellas no sólo una preocupación sino una acción activa en favor del medio ambiente.

\subsection{Ciudadanía Ecológica: Ciudadanía Cuidadora}

Además, el cuidado como paradigma puede contribuir a la construcción de una ciudadanía ecológica, en la que los valores que inspiraron los movimientos antes señalados puedan inspirar a hombres y mujeres en igualdad.

Lo que ha venido a conocerse como política del cuidado tiene dos rasgos distintivos: 1 . Define el cuidado, ante todo, como una acción de la esfera pública y no de la esfera privada, y 2. Aplica la ética del cuidado a escala tanto global como local, desafiando la reducción tradicional del cuidado al principio de proximidad (Moragues y Morgan, 2013, 115).

Joan Tronto es la teórica feminista que más ha contribuido a rescatar el concepto del cuidado del gueto del ámbito privado. Según Tronto $(1994,178)$ repensar la política del cuidado exige que pensemos en el cuidado en el contexto más amplio posible, el de la esfera pública. Es ahí donde aparece el concepto de ciudadanía cuidadora, una ciudadanía preocupada por el bienestar de los otros y otras y de la naturaleza.

Este concepto de ciudadanía cuidadora incluye necesariamente el de ciudadanía ecológica. El concepto de ciudadanía ecológica nos ayuda a completar las concepciones tradicionales de ciudadanía, al incorporar un cuarto elemento a la tríada de componentes clásicos 
de la ciudadanía: civil, política y social (Lister, 1997, 23). Además, la ciudadanía ecológica, desde un punto de vista de la noción de ciudadanía, puede ser vista tanto desde la perspectiva de la participación como de los derechos. Desde el punto de vista de la participación, la amplía, al incluir la relación de la ciudadanía con la naturaleza, lugar donde se contextualiza la idea de ciudadanía cuidadora, en este caso, con el medio ambiente. Desde la perspectiva de los derechos es todavía más conocida, sobre todo desde que se incorporara en la tercera generación de derechos humanos el derecho a un medio ambiente digno.

En contraste con la mayoría de las articulaciones sobre la ciudadanía, la ciudadanía ecológica opera en el ámbito privado tanto como en la esfera pública. Esto se debe principalmente a dos razones. En primer lugar, porque los actos privados pueden tener implicaciones públicas, de modo que pueden relacionarse con la categoría de ciudadanía. En el contexto específicamente ecológico debería quedar claro que las acciones privadas tienen implicaciones públicas con carácter de ciudadanía (Dobson, 2005, 59). La huella ecológica es expresión del impacto que los individuos y grupos humanos ejercen sobre el medioambiente. Este impacto está en función de la producción y reproducción de las vidas de dichos individuos, las cuales tienen una dimensión pública y una privada. Y en segundo lugar, porque algunos de los valores ecológicos como son el cuidado y el sostenimiento de la vida son características de las relaciones del ámbito privado.

El ámbito privado es importante para una ciudadanía ecológica porque las praxis que se generan en su seno contribuyen a desarrollar una lógica de la sostenibilidad de la vida y de relevancia del cuidado de la tierra. «El ciudadano ideal del republicanismo clásico (...) estaba en gran parte libre de la necesidad de trabajar y de cumplir con sus obligaciones corporales (...) desprovisto de las demandas de la vida diaria» (Lister, 1997, 32). La ciudadanía ecológica, por el contrario, se refiere precisamente a la vida diaria. La «esfera de la necesidad» no puede ser trascendida, puesto que es donde la mayor parte de la producción y reproducción de la vida humana tiene lugar. «Esforzarse por satisfacer nuestras demandas materiales» equivale a producir huellas ecológicas que, lejos de alejarnos del reino de la ciudadanía, generan de hecho los tipos de obligaciones más peculiares de ésta (Dobson, 2005, 60). Según Dobson $(2005,61)$ la ciudadanía ecológica aborda el problema a un nivel diferente y más profundo, un nivel en el que la gente hace lo que debe no en función de obtener un premio o evitar un castigo, sino porque es lo correcto. Los consumidores reaccionan ante las señales superficiales de las políticas de incentivos sin preocuparse por entender o comprometerse con la lógica que subyace a esas políticas. Los ciudadanos ecológicos, en cambio, abrigan un compromiso con ciertos principios, e intentarán «hacer el bien» por motivos de justicia más que por conveniencia. Y, - añadiríamos al análisis de Dobson-, también por motivos de interconexión y comunión empática, como hemos señalado anteriormente desde la aportación de la filosofía del cuidar.

Siguiendo a Tronto, Lister y Sevenhuijsen el cuidado como proceso social y práctica de una sociedad civil activa se desarrolla en tres fases que pueden resumirse así: 1 . Ser sensibles y detectar las necesidades sociales de cuidado, 2. Asumir la responsabilidad y la potencialidad para ser agente de cambio, 3. Realizar las acciones pertinentes, es decir, materializar el cuidado. El cuidado, con esta estructura, sirve como base para el logro político de una sociedad mejor. En este sentido, Tronto propone una forma sencilla de definir la ciudadanía, como el proceso en el que los ciudadanos y ciudadanas se comprometen e involucran en 
procesos de cuidado. Una definición de ciudadanía que puede transformar el modo en que pensamos la vida pública y privada, el modo en que entendemos la participación política. Ese análisis del cuidado en el marco de la ciudadanía cuidadora, puede aplicarse sin cortapisas a la dimensión de ciudadanía ecológica, en la que la ciudadanía: 1. Es sensible a las necesidades ecológicas, 2 . Asume las responsabilidades y las potencialidades para ser agentes de cambio y 3. Realiza las acciones de cuidado pertinente. La ciudadanía se definiría como el proceso en el que los ciudadanos y ciudadanas se comprometen e involucran en procesos de cuidado de unos seres humanos con otros y con la naturaleza.

El concepto de ser humano inherente a la ética del cuidado diverge del concepto de individualismo unilateral de muchas teorías políticas. La interrelación y la interdependencia son conceptos centrales en una ética del cuidar. El pensamiento que guía la ética del cuidar es el de seres humanos necesitados unos de otros en el objetivo de conseguir una vida de calidad, y que sólo pueden desarrollarse como individuos a través de relaciones de cuidado con los otros. Selma Sevenhuijsen (2003) acuñó el término autonomía relacional para referirse a este fenómeno. Así, desde la ética del cuidado la relación y la interdependencia entre los seres humanos son la red fundamental sobre la que se basa nuestro accionar y nuestro posicionarnos en el mundo. ¿Por qué cuidamos? «Cuidamos a los otros porque ahí radica la sostenibilidad en un mundo ecológicamente interdependiente» (Moragues y Morgan, 2013, 118). Se evidencia la necesidad de una ética pública del cuidado para que la comunidad internacional pueda enfrentar las amenazas contemporáneas a la integridad ecológica y la justicia social (Moragues y Morgan, 2013, 119).

Las ideas modernas de desarrollo y de ciencia se basan en falsos supuestos, como los que esgrimen que los seres humanos se hallan separados y por encima de la naturaleza. Si hemos visto que una contribución del cuidado en la construcción de una nueva ciudadanía era la de partir de un sujeto relacional, la segunda contribución tendrá que ver con la motivación de ese sujeto para participar de la vida pública. La participación requiere de una motivación, y un importante factor motivador es la preocupación por el bienestar de los seres humanos, la conservación de la naturaleza y el reconocimiento de nuestras capacidades para ser agentes de cambio. La marginación y restricción del valor del cuidado a la esfera privada ha provocado nefastas consecuencias para la esfera pública. La falta de implicación, de compromiso, de motivación, de sentimiento de responsabilidad por lo que nos rodea son los más claros síntomas de este fenómeno. De ahí la importancia de reivindicar el cuidar para reconstruir los fundamentos de una ciudadanía participativa. Mediante las tareas de cuidado el individuo se siente significativo, importante, necesario, y se da cuenta de que tiene cierto poder para modificar la realidad.

Leonardo Boff en un artículo titulado «Tiempo de Crisis - Tiempo de Cuidado» afirmaba que hoy, dada la crisis general, el cuidado es esencial para preservar la continuidad de nuestra civilización. En una época de crisis y, por tanto de reformulación de paradigmas, el cuidado puede colaborar en una crítica radical y una reformulación de la democracia. El cuidado, con sus dos atributos de aumentar nuestra responsabilidad y nuestro sentido de interconexión, es la clave para un sistema democrático participativo. Y sobre todo clave para una ciudadanía consciente de su esferas de responsabilidad y sus múltiples posibilidades de acción ciudadana cotidiana, individual o colectiva, para el bienestar de los más necesitados y el sostenimiento de la naturaleza. 
Son diferentes las propuestas que se van erigiendo como respuesta a los retos medioambientales y a la depredación del planeta por parte del ser humano y en las que el desarrollo de una ciudadanía ecológica alternativa es fundamental. Y es que «ante el derrumbe de la ideología comunista y socialista, el ideario ecológico toma el relevo de la teoría crítica de la sociedad» (Piulats Riu, 2011, 23). Como señala Octavi Piulats «una de las tareas pendientes en el marco de la filosofía occidental es construir una filosofía que englobe y dé razón de la perspectiva ecológica que ha penetrado con fuerza en el imaginario occidental en los últimos decenios» $(2011,24)$. La filosofía del cuidar puede contribuir significativamente, con todas las dimensiones que hemos ido señalando, a la construcción de esa ecosofía.

\section{La Carta de la Tierra}

En el año 2000 nace The Earth Charter, la Carta de la Tierra, que si bien no es la primera declaración internacional sobre medio ambiente, sí es la primera que reconoce la interdependencia entre el medio ambiente, los derechos humanos, el desarrollo y la paz, así como la necesidad de promover soluciones que tengan en cuenta conjuntamente estos elementos indivisibles. Se trata, por tanto, de un enfoque que podríamos calificar, parafraseando a Morin, de sistémico-complejo, alejado de reduccionismos y que nos interpela en el compromiso por la construcción de un nuevo paradigma.

La Carta de la Tierra nace de la profunda preocupación por el camino al que nos conduce la lógica de la acumulación económica y la toma de conciencia de la necesidad de reconducir nuestros pasos hacia un desarrollo humano sostenible. Tomando ese como punto de partida, el marco de sentido y eje transversal que mejor define la Carta de la Tierra no es otro que la ética del cuidado (Fernández Herrería y López López, 2010). Frente a la lógica de la acumulación o de la dominación, la alternativa de la lógica del cuidado y la sostenibilidad de la vida. Como se señala en el Preámbulo «La elección es nuestra: formar una sociedad global para cuidar la Tierra y cuidarnos unos a otros o arriesgarnos a la destrucción».

Pero la elección por el cuidado como eje, no es sólo un voto en favor de la sostenibilidad de la vida, es también un posicionamiento en cuanto al autoconcepto del ser humano y su lugar en el mundo. La Carta de la Tierra refleja la necesidad de esa nueva autoconciencia conectada con la naturaleza que venimos señalando a lo largo del texto, y que Leonardo Boff identificaba con la quinta y última fase en nuestra evolución: la planetaria. La comprensión universalmente compartida sobre la interdependencia entre los seres humanos y la naturaleza. «Esta comunión con la comunidad de la vida es la que hemos considerado como experiencia central de la ética del cuidado» (Fernández Herrería y López López, 2010, 13). Un sujeto relacional, interconectado, consciente de su terrenalidad, que se sabe hecho de tierra - como en la fábula de Higinio - , filamento receptor y hacedor de cuidado en el lienzo de la vida.

\section{Conclusión}

La filosofía del cuidar puede contribuir a la construcción de una ecosofía postandrocéntrica y postantropocéntrica, en la que se disuelvan los reduccionismos y dualismos que han dibujado el pensamiento hegemónico occidental y en la que se refunde el concepto de ser 
humano desde la interconexión y la comunión con la naturaleza. Superar esos dualismos no es tarea sencilla, ya que algunos se construyeron con el hálito de la emancipación y el empoderamiento, tales como el de trascendencia frente a inmanencia, tematizado por Simone de Beauvoir y al que tanto debe el feminismo. Sin embargo, éste como otros de los dualismos de la racionalidad occidental, contiene connotaciones antropocéntricas. Como señala Alicia Puleo renegar de la inmanencia fue «un canto a la libertad que ha inspirado gran parte de nuestra vida pero que encierra el desprecio de la Naturaleza externa e interna» (Puleo, 2005, 206). En esa reconstrucción de una nueva autoconciencia ecológica, el cuidado puede, como paradigma, iluminar nuevas sendas y ayudar a disolver falsos presupuestos.

Cabe recordar, como ya hemos señalado anteriormente, que esta reivindicación del cuidado parte de una defensa de la desgenerización del cuidado, reivindicando el cuidado como valor humano y no como rol de género. Así el reconocimiento de la experiencia y el legado de las mujeres como cuidadoras, parte del reconocimiento de una atribución histórica y una distribución de responsabilidades en el marco de una cultura patriarcal que puede ser en un futuro diferente si nos lo proponemos. Carolyn Merchant en su famosa obra Earthcare señala la importancia de evitar ver la naturaleza como diosa madre, o de atribuir a las mujeres una relación especial-esencial con la naturaleza inaccesible a los hombres (Merchant, 1995). También Susan Griffin en su obra clásica Women and Nature denuncia la asociación mujer y naturaleza que ha caracterizado el pensamiento occidental desde Platón a Freud y que ha contribuido a la subyugación de ambas. Así pues si reconocemos el legado de la historia de las mujeres como cuidadoras, lo hacemos con el propósito de contribuir a la universalización del cuidar como valor humano, por razones de justicia y de felicidad (Comins, 2009), pero también por razones medioambientales.

Será importante para el desarrollo humano y la sostenibilidad de la vida en el planeta educar en esa nueva relación del ser humano con la naturaleza. Edgar Morin en su libro Los siete saberes necesarios para la educación del futuro, señala la necesidad de enseñar la identidad terrenal, como uno de los componentes para reorientar la educación hacia un desarrollo sostenible. Esa identidad terrenal sustituirá la perspectiva individual hegemónica por otra planetaria, en la que exista una conciencia y un sentimiento de pertenencia a nuestra Tierra. Esa educación ambiental no puede ser sino necesariamente educación sentimental y moral, que incluya la educación en la empatía y en los valores del cuidar. Valores necesarios para la formación de una ciudadanía ecológica, capaz de integrar el sentir y las experiencias históricas de las mujeres y de los hombres en pie de igualdad (Puleo, 2005, 211).

\section{Bibliografía}

Arnáiz Ferrer, J. M. (2011), «Bases históricas para la filosofía ecológica» en J. San Martín y T. Domingo Moratalla (eds.), Perspectivas sobre la vida humana. Cuerpo, mente, género y persona, Madrid, Biblioteca Nueva, pp. 34-42.

Bardsley, K. (2013), «Mother Nature and the Mother of All Virtues: On the Rationality of Feeling Gratitude toward Nature», Environmental Ethics, 35 (1), 27-40.

Boff, L. (2002), El cuidado esencial. Ética de lo humano, compasión por la Tierra, Madrid, Trotta.

- (2004), Ética y Moral. La búsqueda de los fundamentos, Santander, Sal Terrae. 
Card, C. (1995), «Gender and Moral Luck» en V. Held (ed.), Justice and Care, Essential Readings in Feminist Ethics, Colorado, Westview Press, pp. 79-100.

Comins Mingol, I. (2010), «El cuidado, eje vertebral de la intersubjetividad humana» en I. Comins Mingol y S. París Albert (eds.), Investigación para la paz. Estudios filosóficos, Barcelona, Icaria, pp. 73-87.

- (2009), «El cuidado en la trayectoria vital: rompiendo moldes con criterios de justicia y felicidad», Recerca, Revista de Pensament i Anàlisi, 9, 81-101.

Comins Mingol, I y París Albert, S. (2012), «Epistemologías para el Humanismo desde la Filosofía para la Paz», Recerca, Revista de Pensament $i$ Anàlisi, 12, 5-11.

Curtin, D. (1996), «Toward an Ecological Ethic of Care» en K.J. Warren (ed.), Ecological Feminist Philosophies, Bloomington, Indiana University Press, pp. 66-81.

Diamond, J. (2006), Colapso, Barcelona, Debate.

Dobson, A. (2005), «Ciudadanía ecológica», Isegoría, 32, 47-62.

Fernández Herrería, A. y López López, M. C. (2010), «La educación en valores desde la carta de la tierra. Por una pedagogía del cuidado», Revista Iberoamericana de Educación, 53 (4), 1-19.

Ferrete Sarriá, C. (2009), «Dificultades y límites en la ampliación de la comunidad moral», Quaderns de filosofia i ciència, 39, 61-72.

Griffin, S. (1978), Women and Nature: The Roaring Inside Her, New York, Harper \& Row.

Keller, E. (1985), Reflections on Gender and Science, New Haven, Yale University Press.

Lister, R. (1997), Citizenship. Feminist Perspectives, London, McMillan.

Magallón, C. (2006), Mujeres en pie de paz, Madrid, Siglo XXI.

Mardones, J.M. (1991), Filosofía de las ciencias humanas y sociales, Barcelona, Anthropos.

Martínez Guzmán, V. (2005), «Filosofía e Investigación para la Paz», Tiempo de Paz, 78, 77-90.

Mellor, M. (1997), Feminism and Ecology, New York, Polity Press.

Merchant, C. (1980), The Death of Nature: Women, Ecology and the Scientific Revolution, New York, Harper \& Row.

- (1995), Earthcare: Women and the Environment, New York, Routledge.

Moragues, A. y Morgan, K. (2013), «El horizonte ético alimentario: la política del cuidado», Papeles de Relaciones Ecosociales y Cambio Global, 121, 113-127.

Morin, E. (2011), Los siete saberes necesarios para la educación del futuro, Barcelona, Paidós.

Mosterín, J. (1994), «La insuficiencia de la filosofía actual», Claves de Razón Práctica, $48,20-27$.

- (2003), «El espejo roto del conocimiento y el ideal de una visión coherente del mundo», Revista Iberoamericana de Ciencia, Tecnología y Sociedad, 1 (1), 209-221.

Novo, M. (2010), Despacio, despacio... 20 razones para ir más lentos por la vida, Barcelona, Obelisco.

- (2006), El desarrollo sostenible. Su dimensión ambiental y educativa, Madrid, Pearson Educación.

Piulats Riu, O. (2011), «Principios para una Filosofía Ecológica del Futuro» en J. San Martín, y T. Domingo Moratalla (eds.), Perspectivas sobre la vida humana. Cuerpo, mente, género y persona, Madrid, Biblioteca Nueva, pp. 21-33. 
Plumwood, V. (1993), Feminism and the Mastery of Nature, London, Routledge.

PNUD (1999), Informe sobre desarrollo humano 1999, Madrid, Mundi-Prensa.

Puleo, A. (2013), «Feminismo y Ecología» en Manzanera Ruiz Roser y otras (coord.) Medio ambiente y desarrollo. Miradas feministas desde ambos hemisferios, Granada, Universidad de Granada.

- (2011a), Ecofeminismo para otro mundo posible, Madrid, Cátedra.

- (2011b), «Ecologías y ecofeminismos» en Amorós Puente, C. y F. Quesada Castro (coord.), Las mujeres como sujetos emergentes en la era de la globalización: nuevas modalidades de violencia y nuevas formas de ciudadanía, Madrid, Instituto de la Mujer, pp. 173-188.

- (2005), «Los dualismos opresivos y la educación ambiental», Isegoría, 32, 201-214.

Rivas Torres, M. (2009), «Wangari Maathai» en M. Mesa Peinado (ed.), 1325 Mujeres Tejiendo la Paz, Barcelona, Icaria, pp. 248-251.

Sevenhuijsen, S. (2003), «The place of care. The relevance of the feminist ethic of care for social policy», Feminist Theory, 4 (2), 179-197.

Shiva, V. (1991), Abrazar la vida. Mujer, ecología y supervivencia, Montevideo, Instituto del Tercer Mundo.

- (2006), Manifiesto para una Democracia de la Tierra. Justicia, sostenibilidad y paz, Barcelona, Paidós.

Tronto, J. (1994), Moral Boundaries: A Political Argument for an Ethic of Care, Nueva York, Routledge.

Ubric Rabaneda, P. (2011), «Gaia y las semillas de la Paz. Las propuestas de Vandana Shiva», en F.A. Muñoz y J. Bolaños Carmona (eds.), Los habitus de la paz. Teorías y prácticas de la paz imperfecta, Granada, Universidad de Granada, pp. 341-355.

Warren, K. (1987), «Feminism and Ecology: Making Connections», Environmental Ethics, 9 (1), 3-20. 